レター

\title{
重み付け尤度関数と定在波を用いた可聴音による二次元環境認識
}

\author{
岸波華 彦*1 系山克寿*1 西田健 次*1 中 臺一 博*1*2 \\ Two-Dimensional Environment Recognition by Audible Sound with \\ Weighted Likelihood Function and Standing Wave
}

Hidehiko Kishinami*1, Katsutoshi Itoyama*1 $^{* 1}$ Kenji Nishida*1 and Kazuhiro Nakadai*1*2

\begin{abstract}
In recent years, many kinds of sensors have been studied to recognize the environment, and they are used for AR and VR applications and for SLAM. Although ultrasonic signals with high directivity and high resolution are often used, there are problems such as ultrasonic exposure and grating noise at the rising edge. In this paper, we propose a new active sensing method based on audible sounds that is robust to environmental noise by combining weighting likelihood functions and standing waves. Compared to ultrasonic signals, audible sound tends to spread out, which leads to misalignment of distance estimates and loss of map consistency over time. Therefore, we derive the effective azimuth angle based on the directional characteristics of the speaker and calculate the likelihood of the presence or absence of obstacles using the observation model. In addition, we introduce occupancy grid mapping to produce a map that best explains the estimated distances. We performed real-world two-dimensional environment recognition experiments using the proposed method to detect and map surrounding obstacles, and showed the effectiveness of the method.
\end{abstract}

Key Words: Audible Sound, Spatial Recognition, Occupancy Grid Mapping, Two-dimensional Environment Recognition

1. は じめに

空間認識に基づく屋内の構造情報の取得は, 様々な応用が期待 できる重要な技術である。中でも屋内構造の認識はロボットの 自己位置推定への応用 [1] や拡張現実 (AR), 仮想現実 (VR) [2] への応用が可能なため, 大きな関心が寄せられている.

既存の研究ではカメラや Lidar などを用いた屋内の地図を作 成する手法が提案されているが [3] [4], これらのセンサは高価な ことに加えてカメラは照明の影響を受けやすく, プライバシー 問題が発生する．また， Lidar は透明な素材の検出が困難で誤作 動を起こした場合に危険なため，人が生活するような屋内での 利用に適しているとは言えない。一方で音響信号を用いた距離 測定は環境雑音の影響を受けるものの，環境光の影響を受けに くく, またカメラやレーザの測定に使われる機器に比べると安 価に測定をすることができる，さらに，カメラやレーザでは検 出が難しい光を透過するガラスなどの材質の物体が存在しても 利用可能であるというメリットがある．音響信号の中でも人間 の耳に聞こえない高い周波数帯の超音波は距離推定の分解能が 良く，低周波数域に多く存在する環境ノイズの影響も受けにく いことから, 距離推定に広く利用されている [5]. 一方で, 出力

原稿受付 2020 年 8 月 19 日

*1東京工業大学 工学院 システム制御系

*2(株) ホンダ・リサーチ・インスティチュート・ジャパン

${ }^{* 1}$ Department of Systems and Control, School of Engineering,

Tokyo Institute of Technology

${ }^{* 2}$ Honda Research Institute Japan Co.

口 本論文は新規性（実証実験分野）で評価されました。

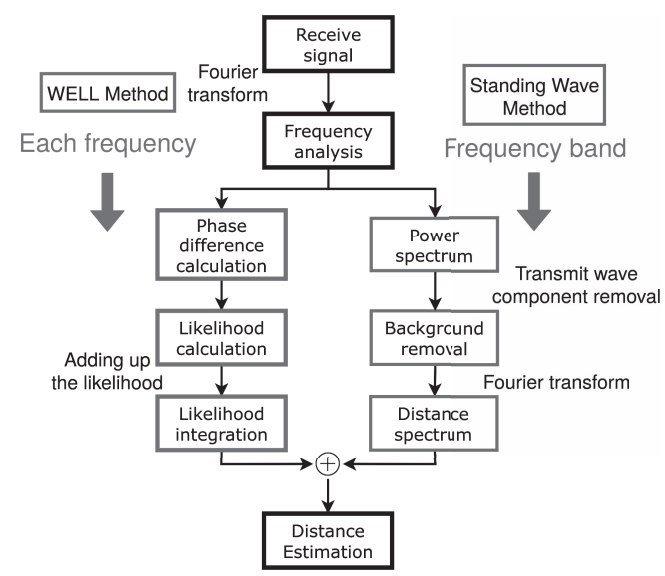

Fig. 1 Overview of one-dimensional distance estimation

時の立ち上がり音が耳障りであることに加えて，人間の耳では 検知できない音であるがゆえに，知らない間に大音量の音響信 号を浴びて超音波曝露になり，頭痛や吐き気などの症状を引き 起こす原因になる $[6]$. このため超音波を用いた距離測定は人が 多い環境での実施に適しているとは言い難い. 可聴音を信号と して使用した場合, 耳障りでない音での距離推定が可能になる. また，誤って大音量を出してしまった場合でもすぐに気づくこ とができ, 耳をふさぐなどして曝露の危険性を下げることがで きるので，人が生活するような環境での実施に向いている. 可 聴音を用いた距離測定は環境ノイズの影響を受けやすく，信号 の位相差から距離が求まっても波長が長いため, 推定距離が一 
意に定まらないという問題がある $[7]$. この問題を解決する手法 として, 定在波法 [8] と WELL (WEighted LikeLihood) 法 [9] を組み合わせることでノイズに対して頑健で距離推定を一意に 決定可能な手法を提案した [10]. 本研究ではこの手法を二次元 環境認識に応用したアクテイブセンシング手法を提案し，実環 境における二次元環境認識実験でその有効性を示す.

\section{2. 一次元距離推定手法の概要}

この章では一次元距離推定手法 [10] の概要を述べる．この手 法はスピーカーとマイクロフォンを組み合わせた装置を用いる. スピーカーから対象物に向けて発した送信波と，その送信波が 対象物で反射して装置に戻ってきた受信波を用いて距離を推定 する。送信波には周波数を線形に変化させるチャープ信号を用 いる.ノイズに対して頑健な WELL 法 [9] と距離を一意に決定 可能な定在波法 [8] を組み合わせることでこれらの性質を両立 させる. Fig. 1 にこの距離推定手法のフローチャートを示す. 各周波数について WELL 法を適用して距離についての尤度関 数を求め, 周波数の帯域について定在波法を用いて距離を推定 し，その近傍で尤度が最大になる箇所を距離推定解とする。

\section{3. 二次元環境認識手法}

上述の距離推定手法を用いた二次元地図作成手法について述 ベる．可聴音は超音波に比べて広く拡散するため，スピーカー 面の法線方向から離れた物体からの反射が距離推定に影響を与 え, 整合性の取れた二次元の地図作成が困難になる。提案手法 はスピーカーの指向特性に基づいて有効方位角（ビームの指向 性）を導出し，観測モデルを用いて障害物の有無の尤度を計算 する.これに Occupancy grid map [11] を導入することで推 定值を最もよく説明できる地図を作成する。これらを組み合わ せることで指向性が低い可聴音でも整合性の取れた二次元の地 図作成の実現を目指す. Fig. 2 に提案手法のフローチャートを 示す.

\section{1 ビームの指向性}

スピーカーから送信される音の指向性についてモデリングす る. スピーカーの幅長を $2 a$, 波数を $k$ とする. $f$ を周波数, $c$ を音速とすると $k=2 \pi f / c$ と表される. 距離 $r$, 角度 $\theta$ 方向 での音圧の振幅は Eq. (1) で近似できる [7].

$$
A_{k, a}(r, \theta) \simeq \frac{e^{-j k r}}{r} \int f(y) e^{j k y \sin \theta} d y
$$

$f(x)$ はスピーカー面での振幅分布となり, Eq. (2) で表される.

$$
f(x)=\left\{\begin{array}{cc}
1 & -a \leq x \leq a \\
0 & a<|x|
\end{array}\right\}
$$

Eq.（2）を Eq.（1）に代入すると Eq.（3）が得られる.

$$
A_{k, a}(r, \theta) \simeq \frac{e^{-j k r}}{r} \int_{-a}^{a} e^{j k y \sin \theta} d y
$$

$A_{k, a}(r, \theta)$ において, 振幅項のみを取り出し, 最大值が 1 とな るように正規化すると, 角度に対する音波振幅の応答である指 向性関数 $R_{k, a}(\theta)$ は

$$
R_{k, a}(\theta)=\frac{\sin (k a \sin \theta)}{k a \sin \theta}
$$

Fig. 3 に $k$ と $a$ を示す. 最初の音圧が 0 になる点は $\theta=$ $\arcsin (0.5 c /(f a))$ となる. これにより音源の大きさが大きくな

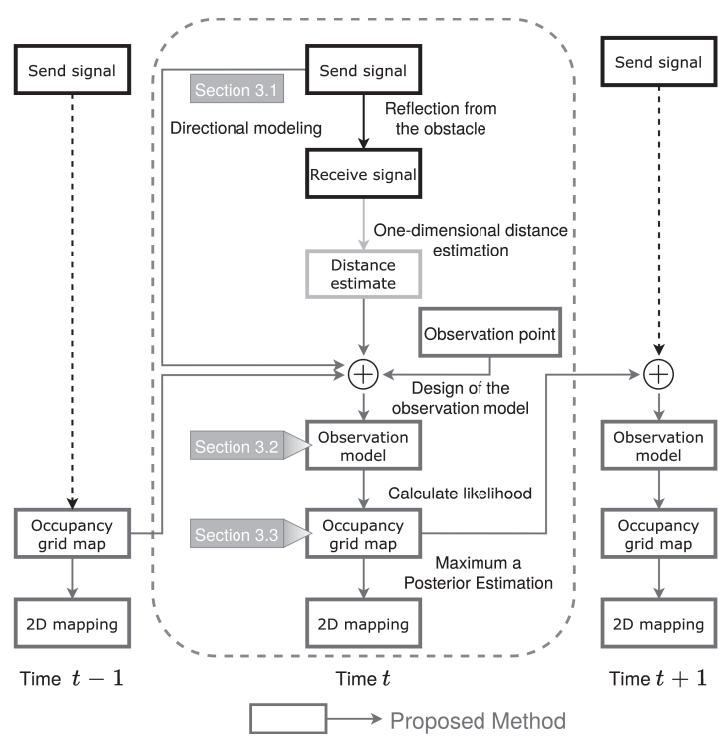

Fig. 2 The flowchart of the Proposed Method

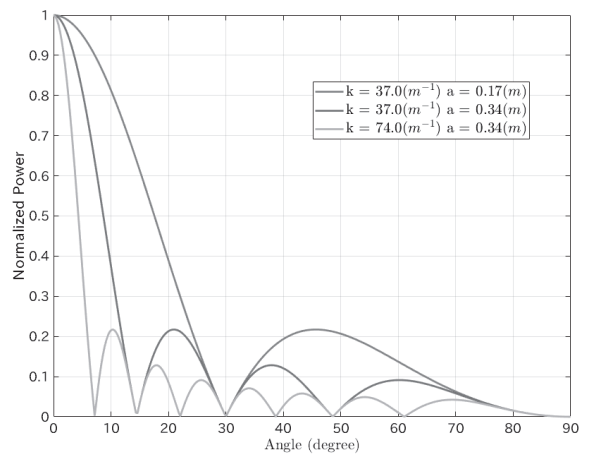

Fig. 3 Image of the directionality of sound waves

るほど，周波数が高くなるほど，送信音の指向性が高くなるこ とが分かる.

\section{2 観測モデル}

上述のように可聴音ではビームの指向性が低く, 音が広がって しまうため, 得られた推定距離をそのまま使うと時間を追うごと に地図の整合性が取れなくなってしまう。そこで，ロボティク スの分野で広く用いられている観測モデルと Occupancy grid map を用いて二次元の地図作成を行う.

グリッドで分けられた地図の各セルの障害物存在の有無を $\mathbf{m}_{n} \in\{0,1\}(1 \leq n \leq N)$ と表す. 観測モデルは地図と観測 者の位置が与えられたときにどのような推定值が得られるのか という確率分布である. 地図 $m=\mathbf{m}_{1}, \mathbf{m}_{2}, \ldots, \mathbf{m}_{N}$ と観測 者の位置 $x_{t} \in \mathbb{R}^{3}$ が与えられたときの観測值 $z_{t}$ の確率分布 $p\left(z_{t} \mid x_{t}, m\right)$ について考える.この確率分布は以下の二つの確率 分布の重み付き混合分布とする.

- $p_{\text {hit }}$ : センサ固有の推定誤差の確率分布

- $p_{\text {short }}$ : 予期しないオブジェクトによる推定誤差の確率分布 センサ固有の推定誤差は真の観測值 $\hat{z}_{t}$ に対する誤差を $\epsilon$ と おくと

$$
z_{t}=\hat{z}_{t}+\epsilon
$$

と表す．真の観測值 $\hat{z}_{t}$ は位置 $x_{t}$ からビームを放ったとき，ビー ムの有効方位角内のセル $m_{b}$ を用いて Eq. (6) で表される.

$$
\hat{z}=\min _{\mathbf{m}_{o} \in m_{b}}\left|x_{t}-\mathbf{m}_{o}\right| \text { s.t. } \mathbf{m}_{o}=1
$$




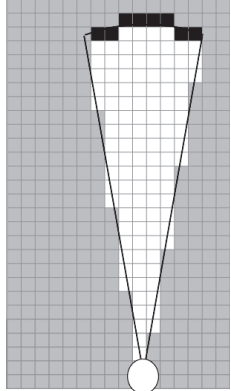

(a) A map made from a single observation

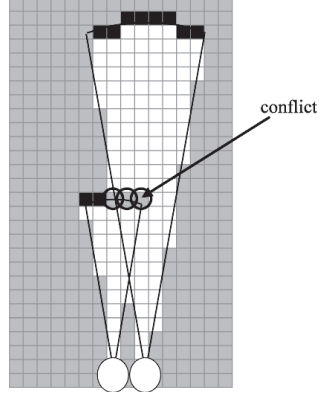

(b) A map with discrepancies caused by observations

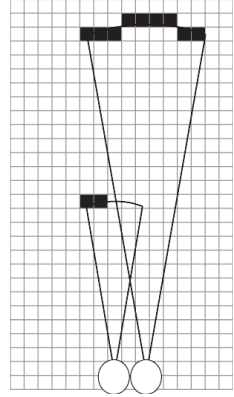

(c) Occupancy grid mapping with maximum posterior probability estimation

Fig. 4 Inconsistencies due to maps and observations [11]

誤差が平均 0 , 分散 $\sigma_{\text {hit }}^{2}$ の正規分布に基づいて発生すると仮 定すると $p_{\mathrm{hit}}\left(z_{t} \mid x_{t}, m\right)$ は Eq.（7）のように表される.

$$
p_{\text {hit }}\left(z_{t} \mid x_{t}, m\right)=\mathcal{N}\left(z_{t} \mid \hat{z}_{t}, \sigma_{\text {hit }}^{2}\right)
$$

センサと地図として描写すべき物体との間に動的物体などの 予期しないオブジェクトが存在すると，よりセンサの近くにあ るオブジェクトまでの距離が計測されてしまい，このような計 測值は地図作成に悪影響を与える。このような動的物体が存在 すると，本来計測されるべき距離がより小さな值に置き換わる ことはあるが，逆に大きな值に置き換わることはない，そこで， このようなオブジェクトが存在した場合の観測值の分布を，パ ラメーター $\lambda_{\text {short }}$ を用いて Eq.（8）で表す.

$$
\begin{aligned}
p_{\text {short }}\left(z_{t} \mid x_{t}, m\right) & =\left\{\begin{array}{cc}
\eta \lambda_{\text {short }} \exp \left(-\lambda_{\text {short }} z\right) & \text { if } 0 \leq z \leq \hat{z} \\
0 & \text { otherwise }
\end{array}\right. \\
\eta & =\frac{1}{1-\exp \left(-\lambda_{\text {short }} \hat{z}\right)}
\end{aligned}
$$

これら二つの確率分布 $p_{\text {hit }}\left(z_{t} \mid x_{t}, m\right), p_{\text {short }}\left(z_{t} \mid x_{t}, m\right)$ の重み 付き混合により観測モデル $p\left(z_{t} \mid x_{t}, m\right)$ を表す.

$$
\begin{gathered}
p\left(z_{t} \mid x_{t}, m\right)=\alpha_{\text {hit }} p_{\text {hit }}\left(z_{t} \mid x_{t}, m\right)+\alpha_{\text {short }} p_{\text {short }}\left(z_{t} \mid x_{t}, m\right) \\
\text { s.t. } \quad \alpha_{\text {hit }}+\alpha_{\text {short }}=1
\end{gathered}
$$

\section{3 Occupancy grid mapping}

Occupancy grid mapping とは，ノイズを含むセンサ観測值 から整合性がとられた地図を生成する手法である.グリッドで 分けられたフィールドの各格子 (occupancy grid) に対して, その場所における物体の有無をバイナリ確率変数で表現する. Eq.（10）を用いて地図 $m^{*}$ が得られる.

$$
m^{*}=\underset{m}{\arg \max } \log p\left(m \mid z_{1: t}, x_{1: t}\right)
$$

$p(m \mid x, z)$ についてベイズの定理を適用すると, Eq. (11) が得 られる。観測者の位置は地図に影響を与えないので $p(m \mid x)=$ $p(m)$ とした.

$$
\begin{aligned}
p(m \mid x, z) & =\frac{p(z \mid m, x) p(m \mid x)}{p(z \mid x)} \\
& =\eta^{*} p(z \mid x, m) p(m) \\
\text { s.t } \quad \eta^{*} & =\frac{1}{p(z \mid x)}
\end{aligned}
$$

$p(m)=0.5$ とし，Eq.（11）を Eq.（10）に代入して得られた Eq.（12）の最大事後確率推定により地図を生成する.

$$
\mathbf{m}_{i}=\underset{k=0,1}{\arg \max } \sum_{j=1}^{t} \log p\left(z_{j} \mid x_{j}, m \text { with } \mathbf{m}_{i}=k\right)
$$

これを Fig. 4 で説明する. 最初に観測モデルを用いて Fig. 4 (a) のような地図を作成することができる，このとき，

・白色：観測から何も障害物がないと考えられるセル.

・黒色：観測から障害物があると考えられるセル。

・灰色：障害物の有無が不明なセル.

を示す．推定を繰り返す事で Fig. 4(b) のようにある推定では 障害物があると判断された場所がほかの推定では障害物がない というように推定結果に矛盾が生じる場合がある．特に今回扱 う音などの広がりを持つセンサでは起きやすい.この矛盾が生 じたセルについて最大事後確率推定を行うことで, Fig. 4 (c) の ように観測したデー夕を最もよく説明可能な地図を作成する.

\section{4. 評 価 実 験}

実環境でスピーカーとマイクロフォンを用いて障害物までの 距離を推定し, 二次元の地図作成の検証を行った.

\section{1 実験環境}

実験環境を Fig. 5 に示す。立てた机を障害物とみなして実験 装置の周囲に配置した．Fig. 5 (c) に実験環境の平面図と座標系 を示す. 実験装置を Fig. 6 に示す。スピーカーはSony SRSX2 を使用し, マイクには MEMS マイクロフォンを使用した. MEMS マイクロフォンをシステムインフロンティア社製の多 チャンネル音響信号収録装置 RASP-ZX に接続し，同期収録を 行った。音響信号はサンプリングレートを $16[\mathrm{kHz}]$, 量子化ビッ 卜数 24 [bit] で収録した。 また，スピーカーをターンテーブル に取り付け，スピーカーの向きを制御しながらスピーカーとマ イクロフォンで距離推定を行った。

送信する音響信号は線形に周波数が変化するチャープ信号で 送信帯域は $1,000[\mathrm{~Hz}]-3,000[\mathrm{~Hz}]$, 送信時間は 2 秒間とした. また，ノイズ環境下でも提案手法を用いて地図作成が可能か検 証するためスピーカーから送信する音響信号に対して SN 比が $10[\mathrm{~dB}]$ になるようにホワイトノイズを追加した.

実験手順はまず，スピーカーからマイクロフォンに直接入る 直接波の推定を行うため, 反射物が周りにない状態でスピーカー から音を出力し，マイクロフォンで収録した，その後，実験環 境でターンテーブルを 20 度ずつ回して各方向 10 回ずつ, 18 方 向分の計 180 回の距離推定を行い, その中央值を推定結果とし た. 最後に得られた推定結果をもとに二次元の地図を作成した. 地図を作成するにあたって音の指向性関数 $R(\theta)$ は, スピー 


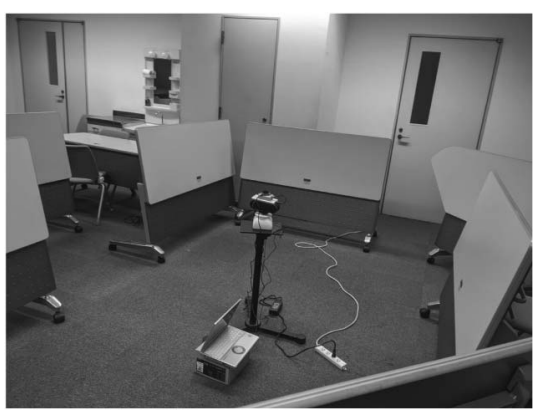

(a) Front direction

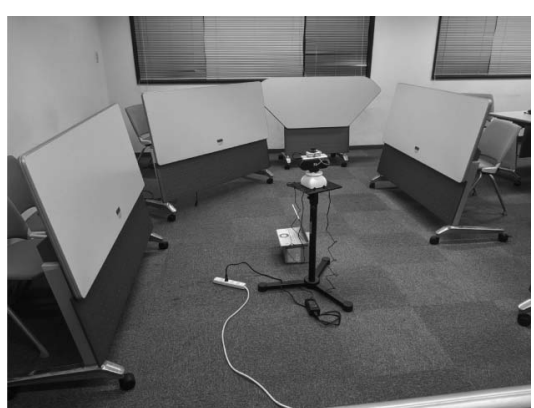

(b) Rear direction

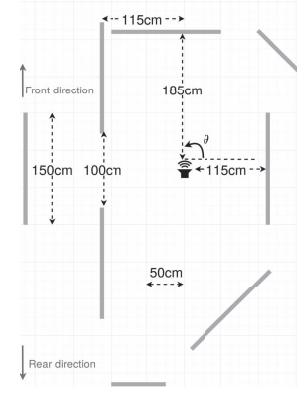

(c) A plan view of the experimental environment

Fig. 5 Experimental environment

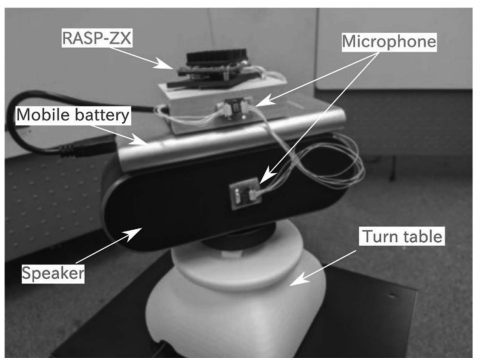

Fig. 6 Experimental device

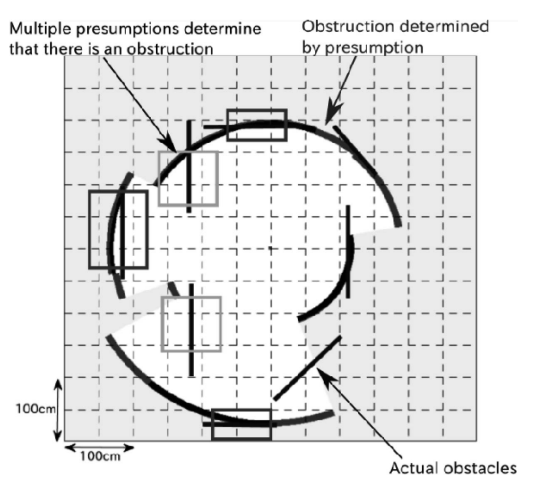

Fig. 7 A map created by the proposed method

カー幅長が $17[\mathrm{~cm}]$, 使用周波数帯の中心周波数 $2,000[\mathrm{~Hz}]$ を Eq. (4)に代入した. スピーカーの指向性関数を Fig. 3 の青線に 示す. 振幅応答が 0 度方向の半分以下になる 20 度をビームの指 向性とした. $\alpha_{\text {short }}=0.4, \alpha_{\text {hit }}=0.6, \sigma_{\text {hit }}=0.15, \lambda_{\text {short }}=0.4$ として観測モデルを設計した.

\section{2 実験結果}

得られた推定データから得られた二次元の地図を Fig. 7 に示 す.ここでのそれぞれの色は

・青：実際に障害物がある場所

・白：障害物がないと判断された場所

・赤：推定によって障害物があると判断された場所

・黒：複数のビームにより障害物があると判断された場所 を示している.

Fig. 7 のピンクの枠で囲まれた箇所ではスピーカーから出力 した音響信号が作るビームと障害物のなす角度が垂直となるた め, 離れた箇所に位置していても適切に検出でき, ノイズ環境下 でも可聴音を用いて周囲の様子をある程度二次元的に認識でき ていることが分かる.一方で緑の枠で囲まれた箇所ではスピー カーから出力した音が作るビームと障害物のなす角度が垂直に ならないため, マイクロフォンに適切に反射波が返らず，距離 推定性能が低下したと考えられる。
この問題の解説策には適切な観測モデルの設計が必要である. 現在, 観測モデルを設計する際にセンサ固有の推定誤差に由来 する確率分布 $p_{\text {hit }}\left(z_{t} \mid x_{t}, m\right)$ の分散 $\sigma_{\text {hit }}^{2}$ をすべての推定で一定 值にしている．正面方向に障害物があるときの 10 回分の推定 結果の分散は小さいが, 上述の問題が発生するケースでは10 回 分の推定結果の分散が大きくなるので, この結果を用いて $\sigma_{\text {hit }}^{2}$ の設計や深層学習を用いたアプローチを取ることで地図作成の 精度改善が可能と考えられる.

\section{5. ま と め}

本稿では可聴音による一次元距離推定手法を応用し, 可聴音 の広がりから空間の尤度計算をすることで, 二次元環境を認識 するアクティブセンシング手法を提案し, 実環境での実験で有 効性を示した. 今後は深層学習のアプローチを取り入れて空間 認識精度の向上，そして三次元空間認識への応用を行っていく 予定である.

謝 辞 本研究は JSPS 科研費 19K12017，19KK0260 およ び 20H00475 の助成を受けた.

\section{参 考 文 献}

[1] 友納正裕: SLAM 入門 ロボットの自己位置推定と地図構築の技術. オーム社, 2018.

[2] https://developers.google.com/ar/, [Online] Last Accessed: 2020/02/17.

[3] J. Biswas and M. Veloso: "Depth camera based indoor mobile robot localization and navigation," IEEE International Conference on Robotics and Automation (ICRA), pp.1697-1702, 2012.

[4] Y.-T. Wang, et al: "A single lidar-based feature fusion indoor localization algorithm," Sensors, vol.18, no.4 p.1294, 2018.

[5] 木村友則, 和高修三, 三須幸一郎, 永塚勉, 田治米徹, 小池光裕：“2 周波数位相検出による高分解能超音波距離計測法”, 日本音響学会誌, vol.52, no.3, pp.179-186, 1996.

[6] M. Daneshmand, et al.: "Medical robots with potential applications in participatory and opportunistic remote sensing: A review," Robotics and Autonomous Systems, vol.95, pp.160$180,2017$.

[ 7] 秋山いわき, 蜂屋弘之, 坂本慎一: アコースティックイメージング. 日本音響学会編，コロナ社，2010.

[ 8 ] 中迫昇, 上保徹志, 篠原寿広 : “可聴音を用いた位相干渉に基づく対 象物までの距離測定”, 電子情報通信学会, vol.9, no.4, pp.330-339, 2016.

[ 9 ] 高尾麻衣子, 干場功太郎，中臺一博：“可聴音を用いた周波数自動選択 に基づく距離推定法の検討”, 第 80 回情報処理学会全国大会, 5Q-03, 2018.

[10] 岸波華彦, 糸山克寿, 西田健次, 中臺一博：“重み付け尤度関数と定在 波を用いた可聴音による距離測定”，SI2019，pp.1495-1500，2019.

[11] S. Thrun, W. Burgard and D. Fox: Probabilistic robotics. MIT Press, Cambridge, Mass., 2005. 